Chapter 6

\title{
Molecular Aspects of Human Alpha-1 Acid Glycoprotein - Structure and Function
}

\author{
Kazuaki Taguchi, Koji Nishi, \\ Victor Tuan Giam Chuang, Toru Maruyama and \\ Masaki Otagiri
}

Additional information is available at the end of the chapter

http://dx.doi.org/10.5772/56101

\section{Introduction}

$\alpha_{1}$-acid glycoprotein (AGP), also called orosomucoid, is an acute phase protein in blood. AGP is comprised of 183 amino acid residues and five N-linked oligosaccharides, with a molecular weight of approximately $44 \mathrm{kDa}$.[1-3] The five carbohydrate chains account for about $40 \%$ of the total mass and render AGP very soluble and confer acidic ( $\mathrm{pI} 2.8-3.8$ ) properties with a net negative charge at physiological $\mathrm{pH} .[1,4]$ While AGP is mainly biosynthesized in the liver and secreted into the circulation, $[5,6]$ other organs including the heart, stomach and lungs have been reported to synthesize and secrete AGP as well.[1] The basal level of AGP is maintained at approximately $20 \mu \mathrm{mol} / \mathrm{L}$ in healthy individuals.

The biological role of AGP is not completely understood, albeit numerous in vitro and in vivo activities such as the inhibition of platelet aggregation, modulation of lymphocyte proliferation and drug transport, have been reported. [4, 7-10] AGP may be involved in various immunomodulatory or anti-inflammation events for the following two reasons. First, the expression of AGP is regulated by both cytokines (interleukin-1, interleukin- 6 and tumor necrosis factor$\alpha$ ) and glucocorticoids, unlike other acute phase proteins including fibrinogen, ceruloplasmin and $\alpha_{2}$-microglobulin, which only by interleukin-6.[11-14] The regulation of AGP production in human hepatocytes by glucagon, interleukin- 8 and the interleukin- 6 is thought to act via mitogen-activated protein kinase (MAPK) pathway. [15] Furthermore, endogenous and exogenous AGP was found to present at sites of inflammation in rats with inflammatory granuloma in a study using fluorescent labeled antibody to AGP or iodine125 labeled AGP. $[16,17]$ Secondly, it is well known that the plasma concentration of AGP is influenced by 
several factors. For example, stresses, inflammation, burns, infections and pregnancy etc. can increase AGP concentration from 2 - to 10 - fold.[18-20] In addition, drugs such as phenobarbital and rifampicin can also increase the concentration of AGP in plasma [21-24], via mechanisms that are independent of the inflammation pathway. [25-28]

Similar to plasma albumin, the binding and transportation of a range of endogenous and exogenous compounds is one of the major physiological functions of AGP.[29] Therefore, drug binding to AGP is important in terms of the correct understanding of pharmacokinetics of drugs, especially during acute phase conditions. We have been investigating the drug-binding specificity and pharmacokinetic properties of AGP using various biophysical and biochemical analytical methods such as spectrophotometry and protein engineering for the past twenty years. Furthermore, we recently succeeded in elucidating the first structure of the AGP (variant A) and its complex with drugs.[30]

In this chapter, a brief overview of the structures of the two AGP variants, characterization of the drug-binding, pharmacokinetic properties and the biological functions of AGP are discussed.

\section{Variants of AGP}

AGP exists as three main genetic variants with the genes located in tandem on chromosome 9.[31] The expression of AGP is under the control of three adjacent genes; AGP-A, which encodes the F1, F2 and S variants, whereas AGP-B and AGP-B' encode the A variant.[32] All three genes are structurally similar to each other, the AGP B/B' genes are identical whereas the AGP A gene contains 22 codon/base substitutions.[33] The precursor product of the AGP-A gene is a 201 amino acid polypeptide with a secretory N-terminal signal peptide of 18 residues. The F1 and S variants are distributed worldwide, but the F2 variant is limited to Europeans and West Asians.[34-36] The F1, F2 and S variants are generally collectively referred as F1*S, because they are encoded by two alleles of the ORM1 gene (AGP-A) differing in less than five amino acids (F1 has Gln-38/Val-174; F2 has Gln-38/Met-174 and S has Arg-38/Val-174). On the other hand, the A variant is coded by the ORM2 gene (AGP-B/B') with approximately 20 amino acid substitutions. The F1*S and A variants differ in their amino acid sequences by approximately 20 residues out of a total of 183 residues (Figure 1).[37]

In most individuals, the molar ratio of the $\mathrm{F} 1{ }^{*} \mathrm{~S}$ and A variants in blood typically ranges from $3: 1$ to $2: 1$.[36, 38] However, the relative proportions of the products of the AGP-A and AGP$\mathrm{B} / \mathrm{B}^{\prime}$ genes have been found to change during acute phase reactions.[39, 40] Vékey and coworkers reported that the molar ratio of the F1*S and A variants was in the vicinity of 8:1 in the plasma of lymphoma, melanoma and ovarian cancer patients.[41] This means that not only the total concentration of AGP but also the molar ratio of the F1*S and A variants may be altered under certain types of pathological conditions. As mentioned in the introduction, the binding and transportation of a range of endogenous and exogenous compounds is one of the major physiological roles of AGP.[29] Furthermore, the F1*S and A variants have different drugbinding selectivity (for details, see section " 4 ", "drug-binding properties").[42] Therefore, an 


\begin{tabular}{|c|c|c|c|}
\hline $\mathrm{E} 1 * \mathrm{~S}$ & QI PLCANLVP & VPITNATLDQ & ITGKWFYIAS \\
\hline A & QI PLCANLVP & VPITNATLDR & ITGKWFYIAS \\
\hline & AFRNEEYNKS & VQEIQATFFY & FTPNKTEDTI \\
\hline & AFRNEEYNKS & VQEIQATFFY & FTPNKTEDTI \\
\hline & FLREYQTRQD & QCIYNTTYLN & VQRENGTISR \\
\hline & FLREYQTRQD & QCFYNSSYLN & VQRENGTVSR \\
\hline & YVGGQEHFAH & LLILRDTKTY & MLAFDVNDEK \\
\hline & YEGGREHVAH & LLFLRDTKTL & MFGSYLDDEK \\
\hline & NWGLSVYADK & PETTKEQLGE & FYEALDCLRI \\
\hline & NWGLSFYADK & PETTKEQLGE & FYEALDCLCI \\
\hline & PKSDVVYTDW & KKDKCEPLEK & QHEKERKQEE \\
\hline & PRSDVMYTDW & KKDKCEPLEK & QHEKERKQEE \\
\hline & $\operatorname{GES}^{183}$ & & \\
\hline & GES & & \\
\hline
\end{tabular}

Figure 1. Amino acid sequence of the human AGP F1*S and A variants. Differences in the amino acid sequences of the two variants are shown in red letters.

increase in AGP concentration and a change in the ratio of the AGP (F1*S and A) variants would affect the pharmacokinetics and pharmacodynamics of drugs that are bound to AGP during inflammation and chronic disease.

\section{Structure}

\subsection{Glycosylation}

AGP has five N-linked glycans that make up more than $40 \%$ of the total mass of the molecule.[3] The N-glycosylation sites of AGP (Asn-15, -38, -54, -75, -85) can carry any one of the glycans shown in Figure 2 corresponding to different degrees of branching (bi-, tri- 
and tetra-antennary).[1] These glycans are structurally heterogeneous due to the great diversity of the terminating sugars. As shown in Figure 2, sialic acid is one of the common terminating sugars, and can be linked to a galactose residue via either an $\alpha 2-3$ or $\alpha 2-6$ linkage. In addition, fucose is another known terminating sugar, which increases the expression of the four sialyl Lewis epitope $\left(\right.$ Lewis $\left.^{x}\right)$ in both acute and chronic inflammation conditions. [43-47] These different degrees of branching and terminating sugars cause the heterogeneity of AGP, at least 20 types of glycan structures in AGP have been reported. $[48,49]$ Halsall and coworkers investigated the distribution of oligosaccharides at the five glycosylation sites in distinct AGP variants using concanavalin A affinity-chromatography, reverse phase-high performance liquid chromatography (RP-HPLC) separation and off-line MALDI-Mass spectrometric analysis, and found that the percentage of the complex glycan type at each site in the three AGP variants was different.[50] In addition, using capillary liquid chromatography-electrospray mass spectrometry to characterize the N-linked glycosylation pattern of AGP, Imre et al. reported that (i) triantennary complextype oligosaccharides predominate at site I (Asn-15) and II (Asn-38), (ii) tetra-antennary complex-type oligosaccharides predominate at sites III (Asn-54), IV (Asn-75) and V (Asn-85), (iii) sites IV and V also present a higher degree of branching and/or longer antennae.[51]

The glycosylation of AGP has been reported to change under various physiological and pathological states. [52] For example, a substantial increase in bi-antennary glycoforms as well as an increase in the degree of 3-fucosylation occurs in the early phase of an acute-phase reaction.[53] The AGP in cancer patients (lymphoma, ovarian tumor etc.) was found to have increased both sialylation and fucosylation, and different relative proportions of the total amounts of bi-, tri- and tetra-antennary sequences.[48, 54, 55] Furthermore, other pathological conditions like chronic inflammation, pregnancy, rheumatoid arthritis, alcoholic liver cirrhosis, sepsis are also known to cause changes in AGP glycosylation.[33, 56-60] Whether the changes in AGP glycosylation have any effect on the biological functions of AGP remains unknown. However, the presence of glycans has been reported to affect the conformational stability and post-translational modification of the folding process of glycoproteins, which include HIV-1 type-glycoprotein 123, quercetin 2, 3-dioxygenase, $\alpha_{1}$-antitrypsin and prion protein.[61-64] Therefore, it is highly possible that the changes in AGP glycosylation that occur under various pathological conditions may serve to either protect the AGP protein from exogenous stress or facilitate various immunomodulatory or anti-inflammation events.

\subsection{Protein}

Highly heterogeneous carbohydrate chains of the AGP molecule makes it difficult to reveal the 3D-structure of AGP. For structural determination by X-ray crystallography, the glycans must be removed from AGP using enzymatic methods, but these procedures fail to completely remove all of the glycan structures, due to following reasons; (i) AGP must be denatured and the disulfide bonds must be reduced to allow the enzyme to digest all glycans. (ii) AGP that is enzymatically deglycosylated is much less soluble in water, thereby resulting in uneven digestion and may create a mixture of polymerized forms. Hence, structural data cannot be 
(A) bi-antenna

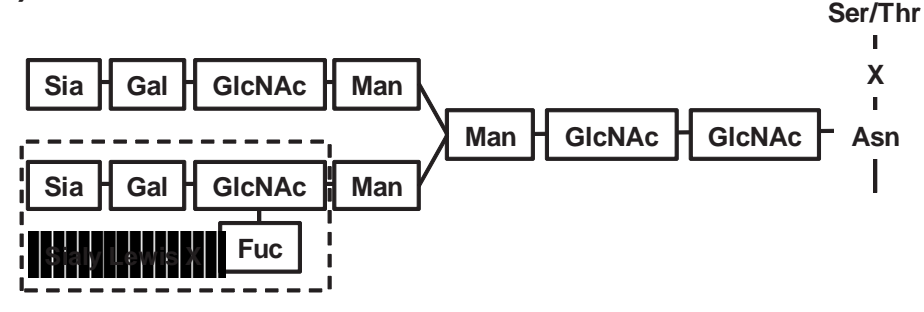

\section{(B) tri-antenna}

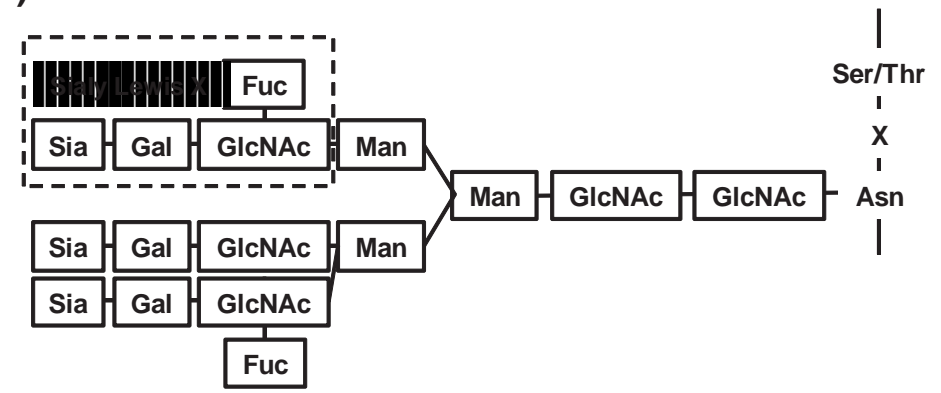

\section{(C) tetra-antenna}

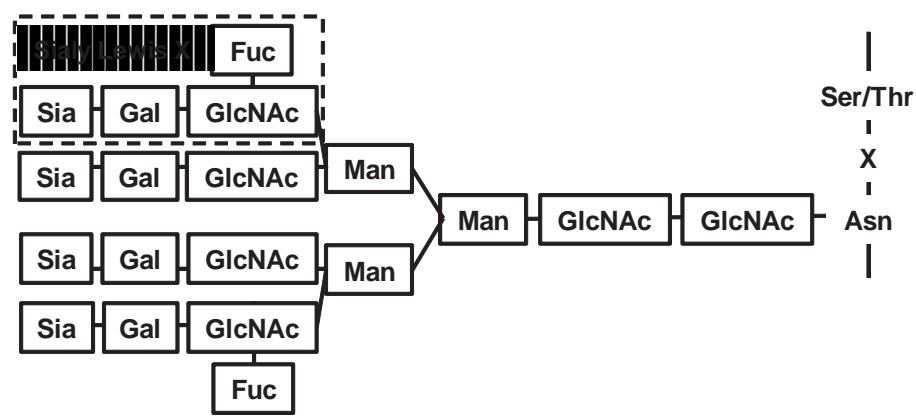

Figure 2. Di-, tri- and tetra-antennary N-linked complex glycans of human AGP. Dotted frame shows Sialy Lewis X. Man, mannose; GluNAC, N-acetylglucosamine; Fuc, fucose; Sia, sialic acid; Gal, galactose; Asn, asparagines; Ser, serine; Thr, threonine; $X$, any amino acid residue except proline

obtained from enzymatically deglycosylated AGP. In 2003, Kopecky et al. constructed a 3Dstructure model of AGP using a combination of vibrational spectroscopy and molecular modeling, and concluded that folded AGP is a highly symmetrical all-beta protein that is dominated by a single eight-stranded antiparallel beta-sheet.[65] In addition, investigations using circular dichroism (CD) spectra and molecular modeling techniques suggest that AGP has an inherent tendency to form an $\alpha$-helical structure and that His-172 of AGP plays an important role in the formation of an $\alpha$-helical structure.[66-69] 
Skerra and co-workers recently reported the first high-resolution X-ray structure of the recombinant unglycosylated F1*S variant of human AGP expressed from Escherichia coli at a $1.8 \AA$ A resolution (Figure 3A). [70] In addition, we have also determined the crystal structure of a C149R mutant of the human AGP A variant, in which a surface-exposed Cys residue was replaced by an Arg residue (as found in $\mathrm{F} 1^{*} \mathrm{~S}$ variant), using expression systems in Escherichia coli at a resolution of $2.1 \AA$ (Figure 3B). [30] Our findings showed that the F1*S variant has a typical lipocalin folding pattern comprised of an eight-stranded $\beta$-barrel, corresponding to residues $24-32,45-54,58-68,71-82,86-92,95-103,109-114$, and 123-128, respectively. On the other hand, the A variant is composed of eight $\beta$-strands, corresponding to $23-32,44-54,59$ $68,71-82,87-92,95-102,109-114$, and 123-128, respectively. In addition, the F1*S variant contains the characteristic $\alpha$-helix comprises residues 135-148 that packs against the $\beta$-barrel, and the A variant has four $\alpha$-helices, 1-4, corresponding to 15-21,35-42, 135-147. These results suggest that the overall folding pattern of $\mathrm{F} 1 * \mathrm{~S}$ and A variants are the same. It is noteworthy that the binding pocket of the F1*S variant is wide and consists of three lobes (I-III), [70] while, in the A variant, lobes I and II are maintained, but not lobe III.[30] This difference indicates that the binding region of the human AGP A variant is narrower than that of the F1*S variant, a difference that may be a contributing factor to the variants distinctive ligand binding selectivity.

\section{Drug-binding properties}

AGP exists in a mixture of two or three genetic variants. Herve' et al. developed a method for fractionating AGP variants, which permitted the binding of drugs to the A and F1*S variants to be investigated,[71] and showed 35 chemically diverse drugs selectively binding to each variant. [71-73] The A variant showed higher drug binding selectivity than the F1*S variant, even though their structural properties are almost identical under physiological conditions. [74] These findings indicate that the drug-binding selectivity of AGP is dependent on the selectivity of the A variant, and that the $\mathrm{F}{ }^{*} \mathrm{~S}$ variant binds a wider range of drugs. The $\mathrm{X}$-ray crystallographic structures of AGP A and F1*S variants have recently been reported by two different groups showed that the binding pocket of the F1*S variant consists of three lobes (IIII) whereas two lobes (I and II) are involved in the case of the A variant.[30, 70] This result supports the view that the binding selectivity of the A variant is higher than that of the F1*S variant reported by Herve' et al.[71-73] The crystal structures of the human AGP A variant complexed with disopyramide and amitriptyline, which bind to the A variant with a high degree of selectivity, reported by Nishi et al. recently revealed conserved edge-face contacts between the two aromatic rings on the drugs and the aromatic side chains of Phe-112 and Phe-49.[30] In addition, Ser-114 in the A variant is involved in a water-mediated hydrogen bond with the amide group of disopyramide. It is noteworthy that the residue at position 112 and 114 in the $\mathrm{F} 1^{*} \mathrm{~S}$ variant is leucine and phenylalanine, respectively. Therefore, the differences in the amino acid residues between the A and F1*S variants of AGP at positions 112 and 114 appear to be crucial for the high selectivity of the A variant for disopyramide, amitriptyline, and other A variant-specific drugs that contain two aromatic rings with similar configurations. 


\section{(A) F1*S variant}

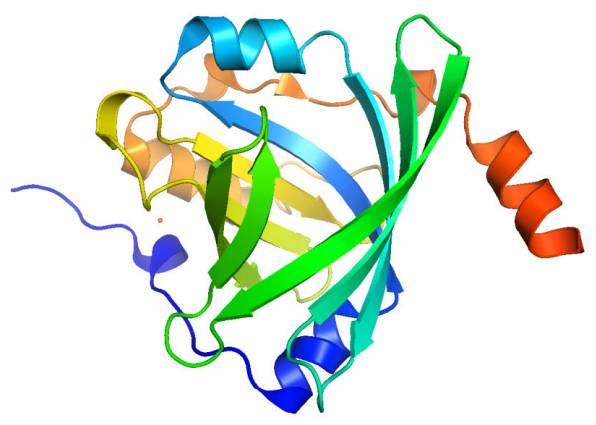

(B) A variant

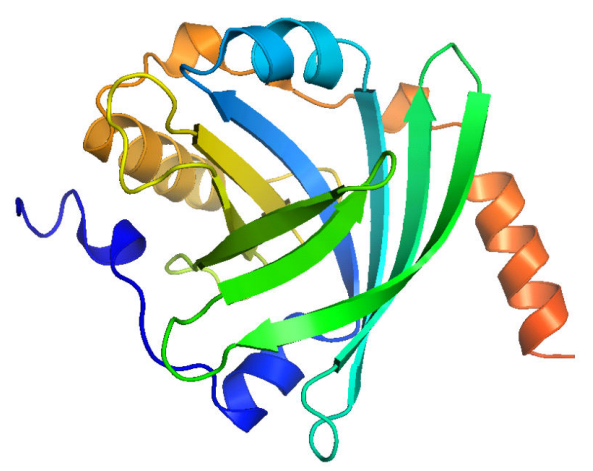

Figure 3. Figure 3 Crystal structures of the human $A G P F 1 * S(A)$ and $A$ variants $(B)$ at a resolution of $1.8 \AA$ and $2.1 \AA$, respectively. Both illustrations were produced with PyMol using the atomic coordinates from Protein Data Bank, 3KQ0 for (A) and 3APX for (B).

Molecular docking and modeling using the crystal structures of the A and F1*S variants are an alternate route to characterizing the drug-binding properties of AGP. Skerra and co-workers modeled the mode of binding of diazepam and progesterone to the $\mathrm{F} 1 * \mathrm{~S}$ variant, and predicted that (i) the polar diazepine ring of diazepam fits into the charged lobe II, resulting in the formation of two hydrogen bounds between the carbonyl oxygen to the side chains of Glu-64 and Gln-66, and that the two ring nitrogens were in contact with Arg-90 and Tyr-127, respectively. (ii) progesterone fitted nicely into lobe I and both Tyr-127 and Ser-40 was crucial for its binding.[70] Furthermore, Azad et al. characterized the binding properties of some polymyxin antibiotics (colistin, polymyxin $\mathrm{B}$, polymyxin $\mathrm{B}_{3}$, colistin methansulfonate, and colistin nonapeptide) with AGP using a combination of biophysical techniques, and developed a molecular 
model of the polymyxin $\mathrm{B}_{3}$-AGP F1*S complex that showed the pivotal role of the $\mathrm{N}$-terminal fatty acyl chain and the D-Phe6-L-Leu7 hydrophobic motif of polymyxin $B_{3}$ for binding to the cleft-like ligand binding cavity of the AGP F1*S variant.[75] In addition to these drugs, molecular docking models of imatinib, 6-mercaptopurine and thymoquinone, -AGP variants complex have also been developed.[76-78]

$\mathrm{CD}$ and fluorescence spectrometry is also a useful tool for examining the drug-binding sites of AGP. We found that electrostatic and hydrophobic forces have an important role in interactions between AGP and basic drugs.[79, 80] Furthermore, the results of fluorescent probe displacement experiments showed that basic drugs strongly displaced not only basic probes, but also acidic probes.[81] On the other hand, acidic probes were displaced by acidic drugs but had no effect on most of the basic probes. The results of the probe displacement study suggest that acidic drugs do not bind to an identical binding region as basic drugs, while acidic drugs do not share a binding region with basic drugs.

Photoaffinity labeling experiments and the use of chemically or genetically modified AGP can provide direct evidence for the specific amino acid residue that is involved in drug binding. The low distribution volumes of 7-hydroxystaurosporine (UCN-01), a protein kinase inhibitor anticancer drug, $[82,83]$ in patients was caused, in part, by its extraordinarily high affinity and specific binding $\left(\mathrm{Ka}=10^{8} \mathrm{M}^{-1}\right)$ to AGP.[84] Chemical modification of all His, Lys, Trp, and Tyr residues of AGP by reacting them with diethylpyrocarbonate, a phenyl isocyanate, 2-hydroxy-5-nitrobenzyl bromide, tetranitromethane, respectively, decreased the binding affinity of AGP to UCN-01.[83] In particular, Trp-modified AGP showed a significant decrease in binding. On the other hand, Zsila and Iwao used induced CD spectra and mutants of AGP to investigate its drug-binding sites, and reported that Trp25 is also involved in the binding of drugs to AGP.[85]

In addition, AGP mutants (W25A, W122A, and W160A)[86] photolabeled with $\left[{ }^{3} \mathrm{H}\right]-$ UCN-01[87] revealed that only W160A showed a marked decrease in the extent of photoincorporation. These results strongly suggest that Trp-160 and Trp-25 play an essential role in the high affinity binding of UCN-01 to AGP. Furthermore, the displacement effects of propranolol, warfarin and progesterone on UCN-01-AGP binding were competitive in nature,[88] indicating that the UCN-01 binding site on AGP is partly overlapped with the binding site for basic drugs, acidic drugs, and steroid hormones.

Another investigation based on photoaffinity labeling experiments with $\left[{ }^{3} \mathrm{H}\right]$-flunitrazepam, also reported that $\left[{ }^{3} \mathrm{H}\right]$-flunitrazepam photolabeled an amino acid residue within the sequence of Tyr91-Arg105.[89] In addition, Kopecky et al., using Raman difference spectroscopy, reported that Trp-122 is possibly involved in the binding of progesterone.[65] Furthermore, Halsall et al. reported that the modification of His-97 with diethylpyrocarbonate was inhibited in the presence of drugs that bind to AGP.[90] This finding suggests that, in addition to Trp-122, His-97 also participates in the binding of drugs. Based on the inconsistent results obtained from above mentioned studies, the binding sites do not appear to be completely separated, but overlap significantly and are influenced by one another, and that AGP has a wide drugbinding site that is common for basic, acidic and neutral drugs. 
The unexpectedly high plasma concentrations of UCN-01 after intravascular administration in a clinical study in relation to preclinical studies (mice, rats, dogs) were found to be due to the high-affinity binding of UCN-01 to human AGP.[84] Investigation of species differences in the drug-binding properties of AGP is one of the important issues for the extrapolation of drug-protein interactions from animals to humans. We previously reported that both dog and bovine AGPs contain a basic ligand binding site and a steroid hormone binding site, which significantly overlaps and affects each other, but do not contain an acid ligand binding site.[91] On the other hand, the ligand binding site on human AGP consists of at least three partially overlapping subsites: a basic ligand binding site, an acidic ligand binding site and a steroid hormone binding site. Zsila et al. reported that chicken AGP is able to bind a broad spectrum of ligands, indicating the existence of a broad common drug binding site.[92]

Drugs bound to AGP have been proposed to be incorporated into cells of organs and tissues via membrane interactions.[93] The interaction of AGP with the membrane induces a structural change in AGP, followed by the release of the bound drug. We recently reported on the interactions of AGP with a model membrane using reverse micelles and liposomes.[68, 69] In the interaction with liposomes, AGP was found to bind to the surface of a membrane via electrostatic interaction. This interaction induced a structural change in AGP, which results in a decrease in its drug-binding capacity. An interesting finding was that AGP underwent a structural change to an $\alpha$-helical form from a $\beta$-sheet form. We also found that the decrease in drug-binding capacity caused by the interaction with the membrane was dependent on the $\alpha$-helix content of the AGP. These findings strongly suggest the existence of the AGP-mediated transport of drugs (Figure 4). It is important, in the future, to reveal how much this system contributes to overall drug transport into tissue.

\section{Disposition}

AGP is mainly biosynthesized in the liver and secreted into the blood circulation.[5, 6] In addition to the liver, other organs including the heart, stomach and lungs etc. are also able to synthesize and secrete AGP.[1] However, the disposition of endogenous AGP after being secreted into the circulation is not fully understood. In 1961, Weisman et al. performed the first pharmacokinetic study of AGP by administering ${ }^{131}$ I-labelled human AGP to convalescent patients, and reported that the half-life of AGP in humans was approximately 5 days.[94] Bree et al. also administered ${ }^{125}$-labelled human AGP ( 8.5 to $10 \mathrm{mg} /$ patients) to seven male patients who were admitted in the intensive care unit due to brain injuries, and reported the half-life of AGP in humans (average half-life; 65 hour, range; 36.3-95.3 hour) was shorter than that observed by Weisman et al..[95] In addition, they found that $60 \%$ of the administered AGP was located within the central compartment while the remaining $40 \%$ was present in the extravascular space like albumin.[96] These data indicated that the half-life of AGP is at least 2-3 days.

Keyler et al. studied the pharmacokinetics of high-doses of human AGP in rats and concluded that AGP could be safely cleared from the body even though the maximum serum AGP concentration after infusion was more than twenty times the normal value.[97] Pharmacoki- 


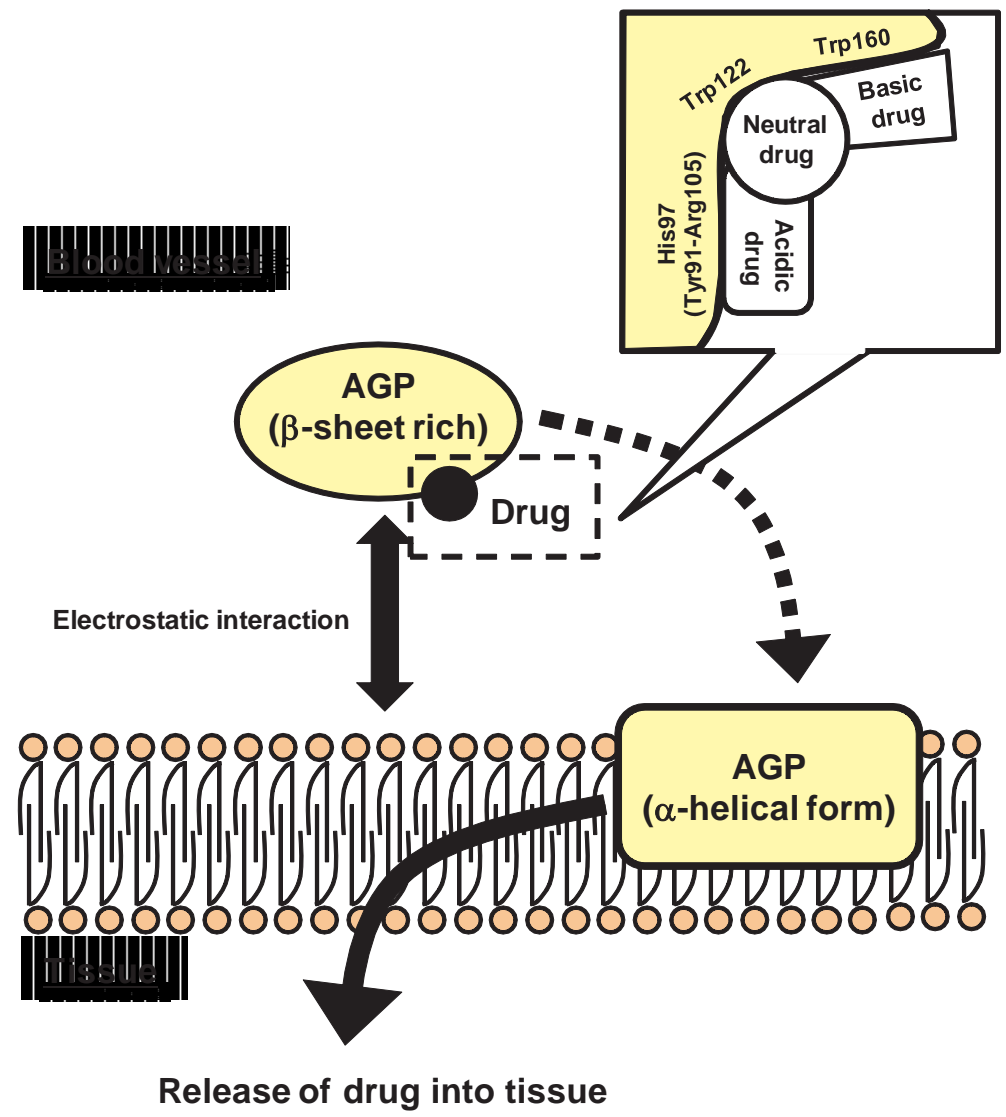

Figure 4. Proposed mechanism of AGP-mediated drug transport and drug-binding region of AGP. (modified from reference 29)

netic studies using mice and rabbits demonstrated that AGP was mainly distributed in the liver.[98, 99] We also clarified that AGP was mainly incorporated into liver parenchymal cells via a receptor-mediated pathway, and the hemoglobin $\beta$-chain located on liver plasma membranes contributes to the intracellular uptake of AGP.[100, 101] These data suggest that AGP is finally taken up by liver parenchymal cells via the hemoglobin $\beta$-chain and is then degraded or eliminated from the body.

The glycans of AGP are known to be largely responsible for the pharmacokinetic properties of the molecule, especially the elimination of AGP. The presence of glycans has been found to contribute in preventing accelerated clearance by glomerular filtration in the kidney, because AGP is a relatively small protein of approximately $44 \mathrm{kDa}$. In order to clarify the role of glycans in the renal elimination of AGP, we prepared a recombinant glycan-deficient AGP by mutating the five Asn residues to Asp residues using a Pichia 
expression system and studied the pharmacokinetics of this recombinant glycan-deficient AGP in mice.[101] The glycan-deficient AGP was eliminated from the blood circulation very rapidly, due to filtration in the kidney. In addition, McCurdy et al. also obtained similar results using glycan-deficient AGP in rabbits.[99]

An asialoglycoprotein receptor has been reported to be associated with the incorporation of AGP into liver tissue.[102] Regoeczi et al. studied the pharmacokinetics of asialo-AGP in chickens and rabbits, and suggested the possibility of the presence of a naturally occurring terminal catabolic point of AGP that was related to hepatic uptake via a hepatic plasma membrane receptor (an asialoglycoprotein receptor).[103] On the contrary, Ikeda et al. reported that the pharmacokinetics of AGP did not change in mice that lacked the asialoglycoprotein receptor compared to wild type mice.[104] In addition, the presence of a sialidase, which digests sialic acid from glycans, has identified in lysosomes [105, 106], cytoplasm [107, 108] and the plasma membrane $[107,109]$, but not in blood. These findings suggest that receptors other than the asialoglycoprotein receptor are involved in the incorporation of AGP into tissues. We investigated the pharmacokinetics of asialo-AGP (sialic acids removed), and agalacto-AGP (both sialic acids and galactose removed) in mice.[98] Whilst the elimination of ${ }^{111}$ In labeled-AGP, -asialo-AGP and -agalacto-AGP from the circulation was suppressed by excess unlabeled AGP, asialo-AGP and agalacto-AGP, respectively, interestingly, agalactoAGP but not asialo-AGP competed with AGP in uptake by the liver, while agalacto-AGP competed with asialo-AGP in uptake by the liver. In addition, the results from a mice study indicated that systemic hyaluronidase treatment decreased the initial clearance of AGP and that AGP administration reduced the binding of hyaluromic acid binding protein to the vessel wall of liver sinusoids. [99] These results suggest that AGP, including N-linked glycans, interact with hyaluronan or hyaluronidase-sensitive component of the vessel wall which influence the transendothelial passage of AGP. Based on these results, a new hepatic elimination pathway involving at least two types of receptors, namely an asialoglycoprotein receptor and another yet to be identified receptor, for AGP was proposed (Figure 5). This unidentified receptor is shared with AGP, and AGP is directly taken up by the liver through such a receptor and not via an asialoglycoprotein receptor.

The oligosaccharide chains of AGP have different degrees of branching (bi-, tri- and tetraantennary) that is influenced by the physiological conditions. The pharmacokinetics of AGP, in turn, is also affected by the proportion of the bi-antennary glycans. Parivar et al. performed the disposition of concanavalin A (Con A)-non-reactive, which contains only one bi-antennary chains, and Con A-reactive human AGP, which contains two or more bi-antennary chains, in normal male rats and acute phase response-activated rats induced by treatment with ethynyloestradiol.[110] The clearance of both Con A-non-reactive and Con A-reactive human AGP was significantly increased in the acute phase response-activated rats compared to normal rats. The clearance of Con A-non-reactive human AGP was marginally higher than Con A-reactive human AGP in the acute phase response-activated rats, but no difference was found in the normal rats. These results indicate that the degree of branching of the glycans alters the disposition of AGP. 


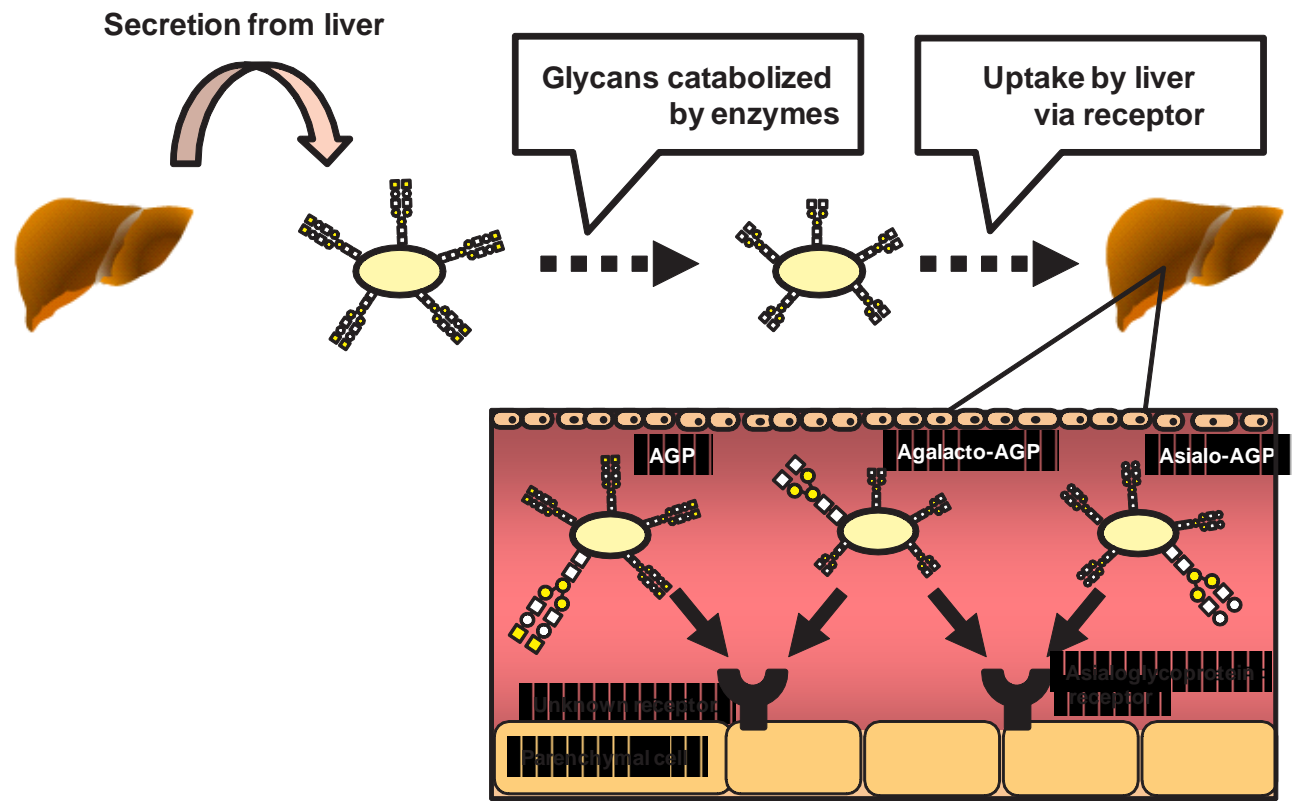

Figure 5. Proposed model of glycan dependent elimination pathway via transporter of AGP. yellow circle, mannose; open square, $\mathrm{N}$-acetylglucosamine; yellow square, sialic acid; open circle, galactose

\section{Biological functions}

The several fold increase of AGP concentration in the circulation during an acute phase response could influence the biological functions of the molecule in humans. [111] Although the detailed biological functions of AGP has not been elucidated completely, the major physiological roles of AGP reported so far involve the binding and transport of a range of drugs and immunomodulating effects. These physiological roles of AGP have been reviewed in section " 4 " and elsewhere. $[1,4]$ Thus, the scope of this section is limited to some interesting observations for other roles.

Van Molle et al. found that bovine AGP with or without glycan chains inhibits the apoptosis of hepatocytes induced by TNF/galactosamine and TNF/actinomycin D in mice via suppressing the activation of caspase 3 and 7, which is a key factor in inducing apoptosis.[112, 113] On the contrary, Kagaya et al. reported that AGP inhibited the cell death of rat primary hepatocytes that had been treated with a chemical toxin (bromobenzene), and the hepatoprotective effect of AGP was lost when the sialic acid groups at the N-glycan chain terminal of AGP were removed.[114] In addition, Karande and co-workers demonstrated the importance of sialylation and glycan size in the manifestation of Glycodelin A for its induced apoptosis due to accessibility to the apoptogenic region. $[115,116]$ These results indicate that AGP potentially possesses anti-apoptosis or cytoprotective effects for hepatocytes which depends on both the 
presence/absence of glycans and the type of terminal sugar. Moreover, Buurman and coworkers demonstrated that human AGP decreases ischemia/reperfusion-induced damage to kidney tissue by suppressing apoptosis, the expression of TNF- $\alpha$ and neutrophil influx.[117, 118] They also found that AGP inhibited the activation of the complement system in the process, and that this protective effect was not associated with the fucosylation of the glycans of AGP. These findings indicate that AGP can be used as a potential new therapeutic intervention in the treatment of acute hepatic and renal failure, as seen after the transplantation of ischemically injured liver and kidneys.

AGP has also been reported to have a protective effect against sepsis from gram-negative infections.[119] Moore et al. showed that AGP interacts with the bacterial lipopolysaccharide (LPS), which is an initiator of the acute inflammatory response associated with septic shock, resulting in the formation of an AGP-LPS complex. This complexation by AGP neutralized the toxicity of LPS and enhanced the clearance of LPS from the body.[120] In addition, Hochepied et al. demonstrated that AGP was effective against a lethal infection by Klebsiella pneumonia and Bacillus anthracis.[119, 121] These results suggested that the increased AGP expression under conditions of an infection facilitates LPS elimination, resulting in a protective effect against endotoxin shock derived from the infection.

The effects of AGP on erythrocyte membranes have also been reported.[122-124] Maeda et al. showed that human AGP is bound to the surface of erythrocytes, which facilitated the passage of erythrocytes throughout artificial membrane filters with various pore diameters under positive pressure, and a pronounced protecting effect against hemolysis during the filtration was also observed.[122, 123] Furthermore, We demonstrated that human, dog and bovine AGPs are able to stabilize the erythrocyte membrane by binding to the surface of the erythrocyte.[124] At physiological concentrations, AGP protects erythrocytes from $\mathrm{H}_{2} \mathrm{O}_{2}$ due to its antioxidant activity.[124, 125] According to these reports, an increase in the AGP content in serum above the normal value found under pathological conditions facilitates the passage of erythrocytes through capillaries, stabilizes erythrocyte membranes and protects against oxidative stress, all of which are favorable properties for the microcirculation.

\section{Conclusions}

Since the initial discovery of AGP, numerous attempts have been made to study characteristics of the molecule, but the actual roles of AGP are yet to be fully understood. Recent advances in scientific technologies such as recombinant protein engineering provide novel and sophisticated tools to further elucidating the molecular and functional aspects of AGP. Among the recent findings, high-resolution $\mathrm{X}$-ray structural data for recombinant the unglycosylated $\mathrm{F} 1{ }^{*} \mathrm{~S}$ and A variants of human AGP would greatly promote the development of AGP research. In the near future, it is expected that AGP, like albumin, fibrinogen and immunoglobulin, will be developed for use in a variety of clinical situations. 


\section{Author details}

Kazuaki Taguchi ${ }^{1,5}$, Koji Nishi $^{1,2}$, Victor Tuan Giam Chuang ${ }^{3}$, Toru Maruyama ${ }^{1,4}$ and Masaki Otagiri ${ }^{1,5,6^{*}}$

*Address all correspondence to: otagirim@ph.sojo-u.ac.jp

1 Department of Biopharmaceutics, Graduate School of Pharmaceutical Sciences, Kumamoto University, Kumamoto, Japan

2 Department of Clinical Pharmacokinetics and Pharmacodynamics, School of Medicine, Keio University, Shinjuku, Tokyo, Japan

3 School of Pharmacy, Faculty of Health Sciences, Curtin Health Innovation Research Institute, Curtin University, Perth, Western Australia, Australia

4 Center for Clinical Pharmaceutical Sciences, Kumamoto University, Kumamoto, Japan

5 Faculty of Pharmaceutical Sciences, Sojo University, Kumamoto, Japan

6 DDS Research Institute, Sojo University, Kumamoto, Japan

\section{References}

[1] Fournier T, Medjoubi NN, Porquet D. Alpha-1-acid glycoprotein. Biochim Biophys Acta 2000; 1482(1-2):157-171.

[2] Israili ZH, Dayton PG. Human alpha-1-glycoprotein and its interactions with drugs. Drug Metab Rev 2001;33(2):161-235.

[3] Schmid K, Nimerg RB, Kimura A, Yamaguchi H, Binette JP. The carbohydrate units of human plasma alpha1-acid glycoprotein. Biochim Biophys Acta 1977;492(2): 291-302.

[4] Hochepied T, Berger FG, Baumann H, Libert C. Alpha(1)-acid glycoprotein: an acute phase protein with inflammatory and immunomodulating properties. Cytokine Growth Factor Rev 2003;14(1):25-34.

[5] Athineos E, Kukral JC, Winzler RJ. Biosynthesis of Glycoproteins. Ii. The Site of Glucosamine Incorporation into Canine Plasma Alpha-1 Acid Glycoprotein. Arch Biochem Biophys 1964;106:338-342.

[6] Sarcione EJ. Sunthesis of alphal-acid glycoprotein by the isolated perfused rat liver. Arch Biochem Biophys 1963;100:516-519. 
[7] Bories PN, Feger J, Benbernou N, Rouzeau JD, Agneray J, Durand G. Prevalence of tri- and tetraantennary glycans of human alpha 1-acid glycoprotein in release of macrophage inhibitor of interleukin-1 activity. Inflammation 1990;14(3):315-323.

[8] Gambacorti-Passerini C, Zucchetti M, Russo D, Frapolli R, Verga M, Bungaro S, et al. Alpha1 acid glycoprotein binds to imatinib (STI571) and substantially alters its pharmacokinetics in chronic myeloid leukemia patients. Clin Cancer Res 2003;9(2): 625-632.

[9] Pos O, Oostendorp RA, van der Stelt ME, Scheper RJ, Van Dijk W. Con A-nonreactive human alpha 1-acid glycoprotein (AGP) is more effective in modulation of lymphocyte proliferation than Con A-reactive AGP serum variants. Inflammation 1990;14(2):133-141.

[10] Williams JP, Weiser MR, Pechet TT, Kobzik L, Moore FD, Jr., Hechtman HB. alpha 1Acid glycoprotein reduces local and remote injuries after intestinal ischemia in the rat. Am J Physiol 1997;273(5 Pt 1):G1031-1035.

[11] Baumann H, Prowse KR, Marinkovic S, Won KA, Jahreis GP. Stimulation of hepatic acute phase response by cytokines and glucocorticoids. Ann N Y Acad Sci 1989;557:280-295.

[12] Kulkarni AB, Reinke R, Feigelson P. Acute phase mediators and glucocorticoids elevate alpha 1-acid glycoprotein gene transcription. J Biol Chem 1985;260(29): 15386-15389.

[13] Kuribayashi T, Tomizawa M, Seita T, Tagata K, Yamamoto S. Relationship between production of acute-phase proteins and strength of inflammatory stimulation in rats. Lab Anim 2011;45(3):215-218.

[14] Stadnyk A, Gauldie J. The acute phase protein response during parasitic infection. Immunol Today 1991;12(3):A7-12.

[15] Wigmore SJ, Fearon KC, Maingay JP, Lai PB, Ross JA. Interleukin-8 can mediate acute-phase protein production by isolated human hepatocytes. Am J Physiol 1997;273(4 Pt 1):E720-726.

[16] Jamieson JC, Turchen B, Huebner E. Evidence for the presence of rat alpha 1-acid glycoprotein in granuloma tissue: a fluorescence microscopy study. Can J Zool 1980;58(9):1513-1517.

[17] Shibata K, Okubo H, Ishibashi H, Tsuda-Kawamura K, Yanase T. Rat alpha 1-acid glycoprotein: uptake by inflammatory and tumour tissues. Br J Exp Pathol 1978;59(6): 601-608.

[18] Cheresh DA, Haynes DH, Distasio JA. Interaction of an acute phase reactant, alpha 1acid glycoprotein (orosomucoid), with the lymphoid cell surface: a model for nonspecific immune suppression. Immunology 1984;51(3):541-548. 
[19] Fey GH, Fuller GM. Regulation of acute phase gene expression by inflammatory mediators. Mol Biol Med 1987;4(6):323-338.

[20] Stekleneva NI, Shevtsova AI, Brazaluk OZ, Kulinich AO. Expression and structuralfunctional alterations of $\alpha$-1-acid glycoprotein at the pathological state. Biopolymers and Cell 2010;26(4):265-272.

[21] Abramson FP. Dose-response behavior of the induction of alpha 1-acid glycoprotein by phenobarbital in the dog. Drug Metab Dispos 1988;16(4):546-550.

[22] Abramson FP, Lutz MP. The kinetics of induction by rifampin of alpha 1-acid glycoprotein and antipyrine clearance in the dog. Drug Metab Dispos 1986;14(1):46-51.

[23] Chauvelot-Moachon L, Delers F, Pous C, Engler R, Tallet F, Giroud JP. Alpha-1-acid glycoprotein concentrations and protein binding of propranolol in Sprague-Dawley and Dark Agouti rat strains treated by phenobarbital. J Pharmacol Exp Ther 1988;244(3):1103-1108.

[24] Komori T, Kai H, Shimoishi K, Kabu K, Nonaka A, Maruyama T, et al. Up-regulation by clarithromycin of alpha(1)-acid glycoprotein expression in liver and primary cultured hepatocytes. Biochem Pharmacol 2001;62(10):1391-1397.

[25] Bertaux O, Fournier T, Chauvelot-Moachon L, Porquet D, Valencia R, Durand G. Modifications of hepatic alpha-1-acid glycoprotein and albumin gene expression in rats treated with phenobarbital. Eur J Biochem 1992;203(3):655-661.

[26] Fournier T, Mejdoubi N, Lapoumeroulie C, Hamelin J, Elion J, Durand G, et al. Transcriptional regulation of rat alpha 1-acid glycoprotein gene by phenobarbital. J Biol Chem 1994;269(44):27175-27178.

[27] Fournier T, Mejdoubi N, Monnet D, Durand G, Porquet D. Phenobarbital induction of alpha 1-acid glycoprotein in primary rat hepatocyte cultures. Hepatology 1994;20(6):1584-1588.

[28] Fournier T, Vranckx R, Mejdoubi N, Durand G, Porquet D. Induction of rat alpha-1acid glycoprotein by phenobarbital is independent of a general acute-phase response. Biochem Pharmacol 1994;48(7):1531-1535.

[29] Otagiri M. A molecular functional study on the interactions of drugs with plasma proteins. Drug Metab Pharmacokinet 2005;20(5):309-323.

[30] Nishi K, Ono T, Nakamura T, Fukunaga N, Izumi M, Watanabe H, et al. Structural insights into differences in drug-binding selectivity between two forms of human alpha1-acid glycoprotein genetic variants, the A and F1*S forms. J Biol Chem 2011;286(16):14427-14434.

[31] Katori N, Sai K, Saito Y, Fukushima-Uesaka H, Kurose K, Yomota C, et al. Genetic variations of orosomucoid genes associated with serum alpha-1-acid glycoprotein 
level and the pharmacokinetics of paclitaxel in Japanese cancer patients. J Pharm Sci 2011;100(10):4546-4559.

[32] Colombo S, Buclin T, Decosterd LA, Telenti A, Furrer H, Lee BL, et al. Orosomucoid (alpha1-acid glycoprotein) plasma concentration and genetic variants: effects on human immunodeficiency virus protease inhibitor clearance and cellular accumulation. Clin Pharmacol Ther 2006;80(4):307-318.

[33] Dente L, Ruther U, Tripodi M, Wagner EF, Cortese R. Expression of human alpha 1acid glycoprotein genes in cultured cells and in transgenic mice. Genes Dev 1988;2(2): 259-266.

[34] Umetsu K, Yuasa I, Nishi K, Brinkmann B, Suzuki T. Orosomucoid (ORM) typing by isoelectric focusing: description of two new alleles in a German population and thermostability in bloodstains. Z Rechtsmed 1989;102(2-3):171-177.

[35] Yuasa I, Umetsu K, Suenaga K, Robinet-Levy M. Orosomucoid (ORM) typing by isoelectric focusing: evidence of two structural loci ORM1 and ORM2. Hum Genet 1986;74(2):160-161.

[36] Yuasa I, Weidinger S, Umetsu K, Suenaga K, Ishimoto G, Eap BC, et al. Orosomucoid system: 17 additional orosomucoid variants and proposal for a new nomenclature. Vox Sang 1993;64(1):47-55.

[37] Schmid K. Human plasma alpha 1-acid glycoprotein--biochemical properties, the amino acid sequence and the structure of the carbohydrate moiety, variants and polymorphism. Prog Clin Biol Res 1989;300:7-22.

[38] Eap CB, Baumann P. The genetic polymorphism of human alpha 1-acid glycoprotein. Prog Clin Biol Res 1989;300:111-125.

[39] Eap CB, Fischer JF, Baumann P. Variations in relative concentrations of variants of human alpha 1-acid glycoprotein after acute-phase conditions. Clin Chim Acta 1991;203(2-3):379-385.

[40] Hanada K, Yamanaka E, Yamamoto N, Minami H, Kawai S, Sasaki Y, et al. Effects of surgery and chronic disease states on the concentrations and phenotype distribution of alpha1-acid glycoprotein: studies in patients with breast cancer and patients with chronic inflammatory disease. Int J Clin Pharmacol Ther 2011;49(7):415-421.

[41] Budai L, Ozohanics O, Ludanyi K, Drahos L, Kremmer T, Krenyacz J, et al. Investigation of genetic variants of alpha-1 acid glycoprotein by ultra-performance liquid chromatography-mass spectrometry. Anal Bioanal Chem 2009;393(3):991-998.

[42] Fitos I, Visy J, Zsila F, Bikadi Z, Mady G, Simonyi M. Specific ligand binding on genetic variants of human alpha1-acid glycoprotein studied by circular dichroism spectroscopy. Biochem Pharmacol 2004;67(4):679-688.

[43] Brinkman-Van der Linden CM, Havenaar EC, Van Ommen CR, Van Kamp GJ, Gooren LJ, Van Dijk W. Oral estrogen treatment induces a decrease in expression of sialyl 
Lewis $\mathrm{x}$ on alpha 1-acid glycoprotein in females and male-to-female transsexuals. Glycobiology 1996;6(4):407-412.

[44] Croce MV, Salice VC, Lacunza E, Segal-Eiras A. Alpha 1-acid glycoprotein (AGP): a possible carrier of sialyl lewis $\mathrm{X}$ (slewis $\mathrm{X}$ ) antigen in colorectal carcinoma. Histol Histopathol 2005;20(1):91-97.

[45] Dage JL, Ackermann BL, Halsall HB. Site localization of sialyl Lewis(x) antigen on alpha1-acid glycoprotein by high performance liquid chromatography-electrospray mass spectrometry. Glycobiology 1998;8(8):755-760.

[46] De Graaf TW, Van der Stelt ME, Anbergen MG, van Dijk W. Inflammation-induced expression of sialyl Lewis X-containing glycan structures on alpha 1-acid glycoprotein (orosomucoid) in human sera. J Exp Med 1993;177(3):657-666.

[47] Ryden I, Pahlsson P, Lundblad A, Skogh T. Fucosylation of alpha1-acid glycoprotein (orosomucoid) compared with traditional biochemical markers of inflammation in recent onset rheumatoid arthritis. Clin Chim Acta 2002;317(1-2):221-229.

[48] Kremmer T, Szollosi E, Boldizsar M, Vincze B, Ludanyi K, Imre T, et al. Liquid chromatographic and mass spectrometric analysis of human serum acid alpha-1-glycoprotein. Biomed Chromatogr 2004;18(5):323-329.

[49] Kuster B, Hunter AP, Wheeler SF, Dwek RA, Harvey DJ. Structural determination of $\mathrm{N}$-linked carbohydrates by matrix-assisted laser desorption/ionization-mass spectrometry following enzymatic release within sodium dodecyl sulphate-polyacrylamide electrophoresis gels: application to species-specific glycosylation of alpha1-acid glycoprotein. Electrophoresis 1998;19(11):1950-1959.

[50] Treuheit MJ, Costello CE, Halsall HB. Analysis of the five glycosylation sites of human alpha 1-acid glycoprotein. Biochem J 1992;283 ( Pt 1):105-112.

[51] Imre T, Schlosser G, Pocsfalvi G, Siciliano R, Molnar-Szollosi E, Kremmer T, et al. Glycosylation site analysis of human alpha-1-acid glycoprotein (AGP) by capillary liquid chromatography-electrospray mass spectrometry. J Mass Spectrom 2005;40(11):1472-1483.

[52] Ceciliani F, Pocacqua V. The acute phase protein alpha1-acid glycoprotein: a model for altered glycosylation during diseases. Curr Protein Pept Sci 2007;8(1):91-108.

[53] van Dijk W, Havenaar EC, Brinkman-van der Linden EC. Alpha 1-acid glycoprotein (orosomucoid): pathophysiological changes in glycosylation in relation to its function. Glycoconj J 1995;12(3):227-233.

[54] Duche JC, Urien S, Simon N, Malaurie E, Monnet I, Barre J. Expression of the genetic variants of human alpha-1-acid glycoprotein in cancer. Clin Biochem 2000;33(3): 197-202. 
[55] Hashimoto S, Asao T, Takahashi J, Yagihashi Y, Nishimura T, Saniabadi AR, et al. alpha1-acid glycoprotein fucosylation as a marker of carcinoma progression and prognosis. Cancer 2004;101(12):2825-2836.

[56] Biou D, Bauvy C, N'Guyen H, Codogno P, Durand G, Aubery M. Alterations of the glycan moiety of human alpha 1-acid glycoprotein in late-term pregnancy. Clin Chim Acta 1991;204(1-3):1-12.

[57] Biou D, Chanton P, Konan D, Seta N, N'Guyen H, Feger J, et al. Microheterogeneity of the carbohydrate moiety of human alpha 1-acid glycoprotein in two benign liver diseases: alcoholic cirrhosis and acute hepatitis. Clin Chim Acta 1989;186(1):59-66.

[58] Jezequel M, Seta NS, Corbic MM, Feger JM, Durand GM. Modifications of concanavalin A patterns of alpha 1-acid glycoprotein and alpha 2-HS glycoprotein in alcoholic liver disease. Clin Chim Acta 1988;176(1):49-57.

[59] Serbource-Goguel Seta N, Durand G, Corbic M, Agneray J, Fegar J. Alterations in relative proportions of microheterogenous forms of human alpha 1-acid glycoprotein in liver disease. J Hepatol 1986;2(2):245-252.

[60] Wieruszeski JM, Fournet B, Konan D, Biou D, Durand G. 400-MHz 1H-NMR spectroscopy of fucosylated tetrasialyl oligosaccharides isolated from normal and cirrhotic alpha 1-acid glycoprotein. FEBS Lett 1988;238(2):390-394.

[61] Fusetti F, Schroter KH, Steiner RA, van Noort PI, Pijning T, Rozeboom HJ, et al. Crystal structure of the copper-containing quercetin 2,3-dioxygenase from Aspergillus japonicus. Structure 2002;10(2):259-268.

[62] Kwon KS, Yu MH. Effect of glycosylation on the stability of alpha1-antitrypsin toward urea denaturation and thermal deactivation. Biochim Biophys Acta 1997;1335(3):265-272.

[63] Lehmann S, Harris DA. Blockade of glycosylation promotes acquisition of scrapielike properties by the prion protein in cultured cells. J Biol Chem 1997;272(34): 21479-21487.

[64] Li Y, Luo L, Rasool N, Kang CY. Glycosylation is necessary for the correct folding of human immunodeficiency virus gp120 in CD4 binding. J Virol 1993;67(1):584-588.

[65] Kopecky V, Jr., Ettrich R, Hofbauerova K, Baumruk V. Structure of human alpha1acid glycoprotein and its high-affinity binding site. Biochem Biophys Res Commun 2003;300(1):41-46.

[66] Aubert JP, Loucheux-Lefebvre MH. Conformational study of alpha1-acid glycoprotein. Arch Biochem Biophys 1976;175(2):400-409.

[67] Nishi K, Komine Y, Fukunaga N, Maruyama T, Suenaga A, Otagiri M. Involvement of disulfide bonds and histidine 172 in a unique beta-sheet to alpha-helix transition 
of alpha 1-acid glycoprotein at the biomembrane interface. Proteins 2006;63(3): 611-620.

[68] Nishi K, Maruyama T, Halsall HB, Handa T, Otagiri M. Binding of alpha1-acid glycoprotein to membrane results in a unique structural change and ligand release. Biochemistry 2004;43(32):10513-10519.

[69] Nishi K, Sakai N, Komine Y, Maruyama T, Halsall HB, Otagiri M. Structural and drug-binding properties of alpha(1)-acid glycoprotein in reverse micelles. Biochim Biophys Acta 2002;1601(2):185-191.

[70] Schonfeld DL, Ravelli RB, Mueller U, Skerra A. The 1.8-A crystal structure of alpha1acid glycoprotein (Orosomucoid) solved by UV RIP reveals the broad drug-binding activity of this human plasma lipocalin. J Mol Biol 2008;384(2):393-405.

[71] Herve F, Caron G, Duche JC, Gaillard P, Abd Rahman N, Tsantili-Kakoulidou A, et al. Ligand specificity of the genetic variants of human alpha1-acid glycoprotein: generation of a three-dimensional quantitative structure-activity relationship model for drug binding to the A variant. Mol Pharmacol 1998;54(1):129-138.

[72] Herve F, Duche JC, d'Athis P, Marche C, Barre J, Tillement JP. Binding of disopyramide, methadone, dipyridamole, chlorpromazine, lignocaine and progesterone to the two main genetic variants of human alpha 1-acid glycoprotein: evidence for drugbinding differences between the variants and for the presence of two separate drugbinding sites on alpha 1-acid glycoprotein. Pharmacogenetics 1996;6(5):403-415.

[73] Herve F, Gomas E, Duche JC, Tillement JP. Evidence for differences in the binding of drugs to the two main genetic variants of human alpha 1-acid glycoprotein. Br J Clin Pharmacol 1993;36(3):241-249.

[74] Kuroda Y, Matsumoto S, Shibukawa A, Nakagawa T. Capillary electrophoretic study on $\mathrm{pH}$ dependence of enantioselective disopyramide binding to genetic variants of human alpha1-acid glycoprotein. Analyst 2003;128(8):1023-1027.

[75] Azad MA, Huang JX, Cooper MA, Roberts KD, Thompson PE, Nation RL, et al. Structure-activity relationships for the binding of polymyxins with human alpha-1acid glycoprotein. Biochem Pharmacol 2012;84(3):278-291.

[76] Fitos I, Simon A, Zsila F, Mady G, Bencsura A, Varga Z, et al. Characterization of binding mode of imatinib to human alpha1-acid glycoprotein. Int J Biol Macromol 2012;50(3):788-795.

[77] Lupidi G, Camaioni E, Khalife H, Avenali L, Damiani E, Tanfani F, et al. Characterization of thymoquinone binding to human alpha(1) -acid glycoprotein. J Pharm Sci 2012;101(7):2564-2573.

[78] Sochacka J, Pawelczak B. Characterization of 6-mercaptopurine binding site on human alpha1-acid glycoprotein (orosomucoid) using molecular docking. Acta Pol Pharm 2012;69(1):161-166. 
[79] Miyoshi T, Sukimoto K, Otagiri M. Investigation of the interaction mode of phenothiazine neuroleptics with alpha 1-acid glycoprotein. J Pharm Pharmacol 1992;44(1): 28-33.

[80] Rahman MH, Miyoshi T, Sukimoto K, Takadate A, Otagiri M. Interaction mode of dicumarol and its derivatives with human serum albumin, alpha 1-acid glycoprotein and asialo alpha 1-acid glycoprotein. J Pharmacobiodyn 1992;15(1):7-16.

[81] Maruyama T, Otagiri M, Takadate A. Characterization of drug binding sites on alpha 1-acid glycoprotein. Chem Pharm Bull (Tokyo) 1990;38(6):1688-1691.

[82] Fuse E, Kuwabara T, Sparreboom A, Sausville EA, Figg WD. Review of UCN-01 development: a lesson in the importance of clinical pharmacology. J Clin Pharmacol 2005;45(4):394-403.

[83] Katsuki M, Chuang VT, Nishi K, Suenaga A, Otagiri M. Tryptophan residues play an important role in the extraordinarily high affinity binding interaction of UCN-01 to human alpha-1-acid glycoprotein. Pharm Res 2004;21(9):1648-1655.

[84] Fuse E, Tanii H, Kurata N, Kobayashi H, Shimada Y, Tamura T, et al. Unpredicted clinical pharmacology of UCN-01 caused by specific binding to human alpha1-acid glycoprotein. Cancer Res 1998;58(15):3248-3253.

[85] Zsila F, Iwao Y. The drug binding site of human alpha1-acid glycoprotein: insight from induced circular dichroism and electronic absorption spectra. Biochim Biophys Acta 2007;1770(5):797-809.

[86] Nishi K, Fukunaga N, Otagiri M. Construction of expression system for human alpha 1-acid glycoprotein in Pichia pastoris and evaluation of its drug-binding properties. Drug Metab Dispos 2004;32(10):1069-1074.

[87] Katsuki M, Chuang VT, Nishi K, Kawahara K, Nakayama H, Yamaotsu N, et al. Use of photoaffinity labeling and site-directed mutagenesis for identification of the key residue responsible for extraordinarily high affinity binding of UCN-01 in human alpha1-acid glycoprotein. J Biol Chem 2005;280(2):1384-1391.

[88] Kurata N, Matsushita S, Nishi K, Watanabe HH, Kobayashi S, Suenaga A, et al. Characterization of a binding site of UCN-01, a novel anticancer drug on alpha-acid glycoprotein. Biol Pharm Bull 2000;23(7):893-895.

[89] Chuang VT, Hijioka M, Katsuki M, Nishi K, Hara T, Kaneko K, et al. Characterization of benzodiazepine binding site on human alpha1-acid glycoprotein using flunitrazepam as a photolabeling agent. Biochim Biophys Acta 2005;1725(3):385-393.

[90] Halsall HB, Austin RC, Dage JL, Sun H, Schlueter KT. Structural aspects of alpha 1acid glycoprotein and its interaction. Proc int Symp on Serum Albumin and Alpha 1acid Glycoprotein, Tokyo Print, Kumamoto, Japan 2000:44-54. 
[91] Matsumoto K, Sukimoto K, Nishi K, Maruyama T, Suenaga A, Otagiri M. Characterization of ligand binding sites on the alpha1-acid glycoprotein in humans, bovines and dogs. Drug Metab Pharmacokinet 2002;17(4):300-306.

[92] Zsila F, Matsunaga H, Bikadi Z, Haginaka J. Multiple ligand-binding properties of the lipocalin member chicken alpha1-acid glycoprotein studied by circular dichroism and electronic absorption spectroscopy: the essential role of the conserved tryptophan residue. Biochim Biophys Acta 2006;1760(8):1248-1273.

[93] Lin TH, Sawada Y, Sugiyama Y, Iga T, Hanano M. Effects of albumin and alpha 1acid glycoprotein on the transport of imipramine and desipramine through the blood-brain barrier in rats. Chem Pharm Bull (Tokyo) 1987;35(1):294-301.

[94] Weisman S, Goldsmith B, Winzler R, Lepper MH. Turnover of plasma orosomucoid in man. J Lab Clin Med 1961;57:7-15.

[95] Bree F, Houin G, Barre J, Moretti JL, Wirquin V, Tillement JP. Pharmacokinetics of intravenously administered 125I-labelled human alpha 1-acid glycoprotein. Clin Pharmacokinet 1986;11(4):336-342.

[96] Berson SA, Yalow RS, Schreiber SS, Post J. Tracer experiments with I131 labeled human serum albumin: distribution and degradation studies. J Clin Invest 1953;32(8): 746-768.

[97] Keyler DE, Pentel PR, Haughey DB. Pharmacokinetics and toxicity of high-dose human alpha 1-acid glycoprotein infusion in the rat. J Pharm Sci 1987;76(2):101-104.

[98] Matsumoto K, Nishi K, Kikuchi M, Watanabe H, Nakajou K, Komori H, et al. Receptor-mediated uptake of human alpha1-acid glycoprotein into liver parenchymal cells in mice. Drug Metab Pharmacokinet 2010;25(1):101-107.

[99] McCurdy TR, Bhakta V, Eltringham-Smith LJ, Gataiance S, Fox-Robichaud AE, Sheffield WP. In vivo clearance of alpha- 1 acid glycoprotein is influenced by the extent of its N-linked glycosylation and by its interaction with the vessel wall. J Biomed Biotechnol 2012; 292730.

[100] Komori H, Nishi K, Uehara N, Watanabe H, Shuto T, Suenaga A, et al. Characterization of hepatic cellular uptake of alpha1-acid glycoprotein (AGP), part 2: involvement of hemoglobin beta-chain on plasma membranes in the uptake of human AGP by liver parenchymal cells. J Pharm Sci 2012;101(4):1607-1615.

[101] Nishi K, Komori H, Kikuchi M, Uehara N, Fukunaga N, Matsumoto K, et al. Characterization of the hepatic cellular uptake of alpha(1) -acid glycoprotein (AGP), part 1: a peptide moiety of human AGP is recognized by the hemoglobin beta-chain on mouse liver parenchymal cells. J Pharm Sci 2012;101(4):1599-1606.

[102] Morell AG, Gregoriadis G, Scheinberg IH, Hickman J, Ashwell G. The role of sialic acid in determining the survival of glycoproteins in the circulation. J Biol Chem 1971;246(5):1461-1467. 
[103] Regoeczi E, Hatton MW, Charlwood PA. Carbohydrate-mediated elimination of avian plasma glycoprotein in mammals. Nature 1975;254(5502):699-701.

[104] Ishibashi S, Hammer RE, Herz J. Asialoglycoprotein receptor deficiency in mice lacking the minor receptor subunit. J Biol Chem 1994;269(45):27803-27806.

[105] Milner CM, Smith SV, Carrillo MB, Taylor GL, Hollinshead M, Campbell RD. Identification of a sialidase encoded in the human major histocompatibility complex. J Biol Chem 1997;272(7):4549-4558.

[106] Pshezhetsky AV, Richard C, Michaud L, Igdoura S, Wang S, Elsliger MA, et al. Cloning, expression and chromosomal mapping of human lysosomal sialidase and characterization of mutations in sialidosis. Nat Genet 1997;15(3):316-320.

[107] Miyagi T, Wada T, Iwamatsu A, Hata K, Yoshikawa Y, Tokuyama S, et al. Molecular cloning and characterization of a plasma membrane-associated sialidase specific for gangliosides. J Biol Chem 1999;274(8):5004-5011.

[108] Monti E, Preti A, Rossi E, Ballabio A, Borsani G. Cloning and characterization of NEU2, a human gene homologous to rodent soluble sialidases. Genomics 1999;57(1): 137-143.

[109] Wada T, Yoshikawa Y, Tokuyama S, Kuwabara M, Akita H, Miyagi T. Cloning, expression, and chromosomal mapping of a human ganglioside sialidase. Biochem Biophys Res Commun 1999;261(1):21-27.

[110] Parivar K, Tolentino L, Taylor G, Oie S. Elimination of non-reactive and weakly reactive human alpha 1-acid glycoprotein after induction of the acute phase response in rats. J Pharm Pharmacol 1992;44(5):447-450.

[111] Kremer JM, Wilting J, Janssen LH. Drug binding to human alpha-1-acid glycoprotein in health and disease. Pharmacol Rev 1988;40(1):1-47.

[112] Van Molle W, Denecker G, Rodriguez I, Brouckaert P, Vandenabeele P, Libert C. Activation of caspases in lethal experimental hepatitis and prevention by acute phase proteins. J Immunol 1999;163(10):5235-5241.

[113] Van Molle W, Libert C, Fiers W, Brouckaert P. Alpha 1-acid glycoprotein and alpha 1-antitrypsin inhibit TNF-induced but not anti-Fas-induced apoptosis of hepatocytes in mice. J Immunol 1997;159(7):3555-3564.

[114] Kagaya N, Kamiyoshi A, Tagawa Y, Akamatsu S, Isoda K, Kawase M, et al. Suppression of cell death in primary rat hepatocytes by alpha1-acid glycoprotein. J Biosci Bioeng 2005;99(1):81-83.

[115] Jayachandran R, Radcliffe CM, Royle L, Harvey DJ, Dwek RA, Rudd PM, et al. Oligosaccharides modulate the apoptotic activity of glycodelin. Glycobiology 2006;16(11): 1052-1063. 
[116] Mukhopadhyay D, SundarRaj S, Alok A, Karande AA. Glycodelin A, not glycodelin $\mathrm{S}$, is apoptotically active. Relevance of sialic acid modification. J Biol Chem 2004;279(10):8577-8584.

[117] Daemen MA, Heemskerk VH, van't Veer C, Denecker G, Wolfs TG, Vandenabeele P, et al. Functional protection by acute phase proteins alpha(1)-acid glycoprotein and alpha(1)-antitrypsin against ischemia/reperfusion injury by preventing apoptosis and inflammation. Circulation 2000;102(12):1420-1426.

[118] de Vries B, Walter SJ, Wolfs TG, Hochepied T, Rabina J, Heeringa P, et al. Exogenous alpha-1-acid glycoprotein protects against renal ischemia-reperfusion injury by inhibition of inflammation and apoptosis. Transplantation 2004;78(8):1116-1124.

[119] Hochepied T, Van Molle W, Berger FG, Baumann H, Libert C. Involvement of the acute phase protein alpha 1-acid glycoprotein in nonspecific resistance to a lethal gram-negative infection. J Biol Chem 2000;275(20):14903-14909.

[120] Moore DF, Rosenfeld MR, Gribbon PM, Winlove CP, Tsai CM. Alpha-1-acid (AAG, orosomucoid) glycoprotein: interaction with bacterial lipopolysaccharide and protection from sepsis. Inflammation 1997;21(1):69-82.

[121] Shemyakin IG, Pukhalsky AL, Stepanshina VN, Shmarina GV, Aleshkin VA, Afanas'ev SS. Preventive and therapeutic effects of alpha-acid glycoprotein in mice infected with B. anthracis. Bull Exp Biol Med 2005;140(4):439-444.

[122] Maeda H, Morinaga T, Mori I, Nishi K. Further characterization of the effects of alpha-1-acid glycoprotein on the passage of human erythrocytes through micropores. Cell Struct Funct 1984;9(3):279-290.

[123] Maeda H, Nishi K, Mori I. Facilitating effects of alpha-1 acid glycoprotein on the passage of erythrocytes through the membrane-filter. Life Sci 1980;27(2):157-161.

[124] Matsumoto K, Nishi K, Tokutomi Y, Irie T, Suenaga A, Otagiri M. Effects of alpha 1acid glycoprotein on erythrocyte deformability and membrane stabilization. Biol Pharm Bull 2003;26(1):123-126.

[125] Pukhal'skii AL, Shmarina GV, Kalashnikova EA, Shiyan SD, Kokarovtseva SN, Pukhal'skaya DA, et al. Effect of semisynthetic analog of alpha(1)-acid glycoprotein on immunomodulatory and antiinflammatory activity of natural glycoprotein. Bull Exp Biol Med 2000;129(5):480-483. 